\title{
Representações sociais do álcool entre estudantes universitárias brasileiras
}

\section{Representaciones sociales del alcohol entre estudiantes universitarias brasileñas}

\section{Social representations of alcohol between Brazilian university students}

\author{
Kairon Pereira de Araújo Sousa \\ ORCID ID: 0000-0003-0779-343X \\ Universidade Federal do Piauí-PPgPsi (UFPI), Brasil \\ Emerson Diógenes de Medeiros \\ ORCID ID: 0000-0002-1407-3433 \\ Universidade Federal do Piauí-PPgPsi (UFPI), Brasil \\ Ludgleydson Fernandes de Araujo \\ ORCID ID: 0000-0003-4486-7565 \\ Universidade Federal do Piauí-PPgPsi (UFPI), Brasil \\ Raquel Pereira Belo \\ ORCID ID: 0000-0003-2586-1563 \\ Universidade Federal do Piauí-PPgPsi (UFPI), Brasil \\ Autor referente: kaironpereira@hotmail.com
}

Historia Editorial Recibido: 16/01/2018 Aceptado: 30/07/2018

\section{RESUMO}

Esta pesquisa teve como objetivo identificar as representações sociais de estudantes universitárias de uma Instituição de Ensino Superior (IES) pública, localizada no estado XX, Brasil, acerca do álcool. Participaram do estudo, 100 estudantes com matrícula ativa nesta instituição. Foram utilizados o Teste de Associação Livre de Palavras (TALP) e questionários. Para a análise de dados, utilizou-se 0
IBM SPSS, versão 21, e a Técnica de Redes Semânticas. Os resultados apontaram diferenças entre as universitárias que não consomem álcool e aquelas que utilizam a substância, na forma como representam o álcool. O primeiro grupo objetivou o álcool, enfatizando os problemas psicossociais decorrentes de seu consumo, enquanto que 0 segundo retrata as sensações 
prazerosas proporcionadas pelo uso da bebida alcoólica. Conclui-se, que tais representações repercutem na relação destas jovens com o álcool, guiando seus comportamentos no tocante ao uso ou não da substância.

Palavras-chave: Álcool; Estudantes Universitárias; Mulheres; Representações Sociais

\section{RESUMEN}

Esta investigación tuvo como objetivo identificar las representaciones sociales de estudiantes universitarios de una Institución de Educación Superior (IES) pública, ubicada en el estado $\mathrm{XX}$, Brasil, acerca del alcohol. Participaron del estudio, 100 estudiantes con matrícula activa en esta institución. Se utilizaron el Teste de Associação Livre de Palavras (TALP) y cuestionarios. Para el análisis de datos, se utilizó el IBM SPSS, versión 21, y la Técnica de las Redes Semánticas. Los resultados apuntaron diferencias entre las universitarias que no consumen alcohol y aquellas que utilizan la sustancia, en la forma como representan el alcohol. El primer grupo objetivó el alcohol, enfatizando los problemas psicosociales resultantes de su consumo, mientras que el segundo retrata las sensaciones placenteras proporcionadas por el uso de la bebida alcohólica. Se concluye, que tales representaciones repercuten en la relación de estas jóvenes con el alcohol, guiando sus comportamientos en lo que se refiere al uso o no de la sustancia.

Palavras clave: Alcohol; Estudiantes Universitarios; Mujeres; Representaciones Sociales

\section{ABSTRACT}

This research aimed to identify the social representations of university students of a public Higher Education Institution (HEI) located in the XX state, Brazil, about alcohol. 100 students participated in the study with active enrollment in this institution. The Teste de Associação Livre de Palavras (TALP) and questionnaires were used. For the data analysis, we used the IBM SPSS, version 21, and the Technique of Semantic Networks. The results showed differences between university students who do not consume alcohol

and those who use the substance in the way they represent alcohol. The first group aimed at alcohol emphasizing the psychosocial problems resulting from their consumption, while the second group portrays the pleasurable sensations provided by the use of the alcoholic beverage. It is concluded, that these representations have repercussions on the relationship of these young women with alcohol, guiding their behavior regarding the use of the substance or not.

Keywords: Alcohol; University Students; Women; Social Representations

\section{Introdução}

relação entre homem e consumo de álcool não é recente. A partir de uma
Lanálise da história, fica perceptível que o álcool sempre ocupou lugar de 
destaque nas sociedades, sendo utilizado pelas pessoas em diferentes contextos, possuindo significados variados, de acordo com cada cultura (Werner, Siqueira, \& Lemes, 2015). Contudo, apesar de haver uma concepção positiva em relação a essa substância, seu uso tem sido objeto de estudo em diferentes áreas do conhecimento científico, em função dos problemas sociais, econômicos e de saúde provocados por seu uso excessivo (Baumgarten, 2010).

O álcool é a droga mais utilizada no mundo todo (Silva, Rodrigues, Jones, Finelli, \& Soares, 2015). Sua ingestão tem ocorrido de forma cada vez mais precoce, tornando-o uma questão de saúde pública (Leite, Leite, Soares, \& Finelli, 2016). Estima-se que o uso abusivo da bebida alcoólica, entre a população mundial, esteja associado ao maior risco de morbidade, mortalidade e incapacidades, responsável por aproximadamente 3,3 milhões de mortes a cada ano. Deste modo, cerca de $6 \%$ de todas as mortes no mundo estão ligadas, direta ou indiretamente, ao consumo abusivo de álcool (Organização Mundial da Saúde [OMS], 2014).

Dados fornecidos pelo II Levantamento Nacional de Álcool e Drogas [II LENAD] (2012), realizado no Brasil, indicaram um aumento do consumo de bebidas alcoólicas na população brasileira, com destaque para o uso nocivo. A pesquisa destacou que cerca de 11,7 milhões de pessoas no país seja dependente da droga.

A substância adquiriu prestígio social por ser um produto consumido por distintos povos, ingerida por pessoas de diferentes faixas etárias. Na legislação brasileira vigente, a substância é identificada como uma droga lícita, cuja comercialização é permitida por lei, com restrição de venda para menores de dezoito anos (Sousa, 2017).

Em literatura especializada, tem sido documentado um aumento de consumo de bebidas alcoólicas, entre a população jovem. Os resultados indicam que o padrão de ingestão de bebidas, sua periodicidade e quantidade utilizada, estão relacionados a vários danos e riscos à saúde (Bertoni \& Santos, 2017). O consumo prejudicial de 
álcool também resulta em acidentes de trânsito, absenteísmo e acidentes de trabalho, envolvimento em brigas, violência intrafamiliar, suicídio, criminalidade, violência sexual, distúrbios emocionais, entre outros (Feijão et al., 2012).

No contexto acadêmico, a substância é apontada como a droga mais utilizada pelos estudantes universitários (Feijão et al., 2012). O consumo de álcool por esse público, bem como as consequências oriundas do uso excessivo, tem motivado a realização de diversas investigações nas últimas décadas, visando identificar os fatores relacionados com a sua preferência (Barros, Barros, Bernardes, Lima, \& Silva, 2012).

No Brasil, os estudos possuem diferentes objetivos: análise dos padrões de consumo, principais fatores relacionados e as consequências do consumo (Baumgarten, 2010); avaliação e descrição dos aspectos estruturais das representações sociais da bebida alcoólica (Rosa \& Nascimento, 2015); a prática de binge alcoólico entre estudantes universitários (Feijão et al., 2012); a relação entre o consumo de álcool e o lazer em estudantes universitários (Pinto, 2013), entre outros.

Esse crescente interesse dos pesquisadores, no estudo do consumo de álcool por estudantes universitários, sinaliza a preocupação do uso excessivo interferir no desenvolvimento integral do acadêmico, comprometendo seu desempenho, bem como seu bem-estar físico e psicológico, produzindo consequências, tanto pessoais quanto sociais.

Ao se analisar a literatura nacional se verificou a inexistência de estudos das Representações Sociais (RS) de consumo de álcool entre estudantes universitárias. Até o término deste manuscrito, não foi encontrada nenhuma pesquisa averiguando as representações sociais da bebida alcoólica, especificamente com esse público, apesar do II LENAD (2012) indicar um aumento do consumo de álcool por jovens do sexo feminino, situando-as na faixa da população mais vulnerável ao padrão de consumo binge drinking - o uso episódico e intensivo de bebidas alcoólicas. Essa escassez de 
estudos sobre as RS entre universitárias de consumo alcoólico motivou a realização dessa pesquisa.

O estudo das RS permite compreender como são construídos os sentidos que os indivíduos criam por algum objeto. Deste modo, conhecer as RS que universitárias brasileiras possuem a respeito do álcool é de suma relevância, considerando-as como influentes em suas práticas em relação ao consumo da substância. Assim, espera-se, com este trabalho, contribuir para subsidiar ações de prevenção e promoção em saúde, direcionadas a essa população, além de contribuir com o arcabouço teórico da psicologia social, por meio do fornecimento de dados empíricos e teóricos das RS do álcool para estudantes universitárias.

As $\mathrm{RS}$ representam uma forma de conhecimento do senso comum que orienta nossa relação com o mundo e com os outros, organizando e guiando comportamentos e comunicações sociais, estabelecidas no cotidiano. É uma forma de saber socialmente elaborada e compartilhada, possuindo valor prático, que permite a construção da realidade social comum a um determinado grupo social (Jodelet, 2001).

Deste modo, elas se constituem em uma forma específica de entender e divulgar aquilo que sabemos, tendo como meta absorver o sentido de mundo, inserindo nele ordem e concepções, que o reproduzam de modo significativo. As RS permitem tornar o não familiar em familiar, apresentando uma conjuntura cognitiva, histórica e cultural, sendo difundida por diferentes modos de comunicação (Moscovici, 2015). Assim, atravessam os discursos, sendo traduzidas pelas palavras e transmitidas em mensagens e imagens de mídias, repercutindo nas condutas e organizações materiais e espaciais (Jodelet, 2001). Embasado nesses pressupostos, este estudo objetivou conhecer, de forma empírica, as representações sociais de estudantes universitárias brasileiras acerca do álcool. 


\section{Método}

\section{Participantes}

A pesquisa contou com 100 estudantes universitárias, matriculadas em diferentes cursos de graduação, de uma Universidade Pública sediada no estado XX, Brasil, escolhidas de forma não-probabilística, por conveniência.

Para a inclusão no estudo foram utilizados os seguintes critérios: ser maior de idade ( >=18 anos), sexo feminino, ser estudante universitária, possuir matrícula ativa na IES, e aceitar, de forma voluntária, colaborar com o estudo. Os critérios de exclusão considerados foram: ser menor de idade, não demonstrar interesse em participar da pesquisa e não preencher completamente os questionários ou apresentar respostas com escrita incompreensível.

As estudantes foram divididas em dois grupos. O primeiro grupo, constituído por universitárias que afirmaram não consumir álcool, contou com 50 participantes, com média de 22,1 anos ( $D P=5,27)$, representando uma amostra relativamente jovem. $A$ maior parte reside com os pais e possui religião (92\%), sendo a maioria evangélica $(50 \%)$.

O segundo grupo, representado pelas universitárias que indicaram ingerir bebidas alcoólicas, também foi composto por 50 estudantes, com média de idade de 20,84 anos $(\mathrm{DP}=3,48)$. O maior índice era de jovens entre 19 e 20 anos de idade. A maioria são jovens solteiras (94\%), pertencentes a cursos da área das ciências biológicas e da saúde (44\%) e residem com os pais (38\%). A bebida mais consumida foi a cerveja (82\%), seguida do vinho (8\%). Em relação ao item "com quem costuma ingerir álcool", a maior parte das participantes indicou os amigos (37\%). A conferência, dos demais dados de ambos os grupos, pode ser realizada através da tabela 1. 
Tabela 1

Dados socidemográficos em função da variável consumo de álcool

\begin{tabular}{|c|c|c|c|c|}
\hline \multirow[t]{2}{*}{ Variável } & \multicolumn{2}{|c|}{ Não Consomem Álcool } & \multicolumn{2}{|c|}{ Consomem Álcool } \\
\hline & Frequência & $\%$ & Frequência & $\%$ \\
\hline \multicolumn{5}{|l|}{ Estado civil } \\
\hline Solteira & 45 & 90,0 & 47 & 94,0 \\
\hline Casada & 5 & 10,0 & 2 & 4,0 \\
\hline $\begin{array}{l}\text { Separada/divorciada } \\
\text { Área do conhecimento }\end{array}$ & - & - & 1 & 2,0 \\
\hline Ciências biológicas e da saúde & 23 & 46,0 & 22 & 44,0 \\
\hline Ciências Humanas & 21 & 42,0 & 17 & 34,0 \\
\hline Ciências Agrárias & 4 & 8,0 & 6 & 12,0 \\
\hline Ciências Sociais Aplicada & 2 & 4,0 & 5 & 10,0 \\
\hline \multicolumn{5}{|l|}{ Reside } \\
\hline Pais & 19 & 38,0 & 19 & 38,0 \\
\hline Outros familiares & 16 & 32,0 & 10 & 20,0 \\
\hline Amigos & 11 & 22,0 & 16 & 32,0 \\
\hline Sozinha & 4 & 8,0 & 3 & 6,0 \\
\hline Namorado & - & - & 2 & 4,0 \\
\hline \multicolumn{5}{|l|}{ Religião } \\
\hline Sim & 46 & 92,0 & 39 & 78,0 \\
\hline Não & 4 & 8,0 & 11 & 22,0 \\
\hline \multicolumn{5}{|l|}{ Tipo de religião } \\
\hline Católica & 19 & 38,0 & 36 & 72,0 \\
\hline Evangélica & 25 & 50,0 & 2 & 4,0 \\
\hline Espírita & 1 & 2,0 & 1 & 2,0 \\
\hline Testemunha de Jeová & 1 & 2,0 & 1 & 2,0 \\
\hline Não tem religião & 4 & 8,0 & 10 & 20,0 \\
\hline \multicolumn{5}{|l|}{ Bebida mais consumida } \\
\hline Cerveja & - & - & 41 & 82 \\
\hline Vinho & - & - & 4 & 8,0 \\
\hline Vodka & - & - & 2 & 4,0 \\
\hline Whisky & - & - & 2 & 4,0 \\
\hline Caipirinha & - & - & 1 & 2,0 \\
\hline \multicolumn{5}{|l|}{ Costuma ingerir álcool } \\
\hline Amigos & - & - & 37 & 74 \\
\hline Familiares & - & - & 8 & 16 \\
\hline
\end{tabular}




\begin{tabular}{llllcc}
\hline Namorado $(\mathrm{a})$ & - & - & 5 & 10 \\
Idade de início do uso de & - & - & 15,42 & 100 \\
álcool & & & & \\
\hline
\end{tabular}

\section{Instrumentos}

Para a coleta dos dados, foram utilizados a Técnica de Associação Livre de Palavras (TALP) e dois questionários (um para estudantes que não consumiam álcool e outro para as que faziam uso de bebida etílica). Conforme procedimentos da TALP e o objetivo da pesquisa, foi utilizado como estímulo indutor a palavra álcool. As participantes foram orientadas a escrever as primeiras cinco palavras que thes surgiam quando o pesquisador pronunciava a palavra-estímulo e, em seguida, hierarquizá-las por ordem de importância, sendo o número 1 a palavra mais importante e 5 a menos importante.

Quanto aos questionários, às estudantes que não consumiam álcool, as questões consistiram de variáveis sociodemográficas, com o intuito de caracterizar a amostra. 0 questionário elaborado para as estudantes que faziam uso de álcool, além das variáveis sociodemográficas, apresentou questões relativas às variáveis sobre álcool (tipo de bebida consumida, com quem costuma inserir álcool e idade de início do consumo).

\section{Procedimentos de coleta de dados}

Inicialmente, um estudo piloto foi realizado a fim de avaliar e aprimorar os instrumentos de coleta de dados. O teste demonstrou que as participantes compreenderam os quesitos propostos, obtendo-se a validade semântica dos mesmos, possibilitando sua aplicação definitiva com o público-alvo.

A autorização para realização do estudo foi obtida junto da direção do campus da IES, local da pesquisa.

Após a anuência do diretor responsável pela IES, as participantes foram abordadas, de forma individual e coletiva, nos diversos espaços da universidade (pátio, 
corredores, biblioteca e salas de aula), e convidadas a colaborar com a pesquisa. Foi explicitado o objetivo do estudo e efetuados os devidos esclarecimentos a respeito do anonimato, sigilo e confidencialidade dos dados fornecidos. Enfatizou-se, também, que a participação no estudo era voluntária, não implicando em custo e/ou qualquer tipo de remuneração aos participantes.

O primeiro instrumento utilizado foi a TALP. Realizou-se um exercício de simulação, com o propósito de familiarizar as participantes com a funcionalidade do instrumento, orientando-as como proceder (Coutinho \& Do Bú, 2017). Para tanto, tomou-se como exemplo a palavra amor. As respondentes foram solicitadas a expressar livremente as cinco palavras que melhor caracterizavam o termo indutor. Salientou-se a importância de se utilizar palavras isoladas ao invés de frases no preenchimento dos espaços.

Em seguida, apresentou-se o estímulo indutor da pesquisa, pedindo-se às participantes que enunciassem as primeiras cinco palavras que lhes viesse à mente, após o pesquisador pronunciar o termo álcool. Estipulou-se o tempo de um minuto, para que cada participante pudesse responder a atividade, tendo em vista, que quanto mais rápida a evocação da resposta, maior o efeito de validade, uma vez que o tempo gasto para refletir e selecionar um termo mais sofisticado pode enviesar os resultados da pesquisa (Coutinho \& Do Bú, 2017). Logo a seguir, as colaboradoras responderam aos questionários. O tempo médio de aplicação dos instrumentos foi de $10 \mathrm{~min}$. Cabe registrar que houve duas recusas de participação na presente pesquisa.

\section{Análise dos dados}

Para a análise dos dados coletados através dos questionários, utilizou-se o programa IBM SPSS, versão 21, realizando-se as análises de estatísticas descritivas, com a finalidade de caracterizar a amostra.

As informações obtidas com a TALP foram transcritas para a planilha do Excel. Em seguida, procedeu-se com a reunião das palavras suscitadas pela TALP, a fim de 
categorizá-las em unidades semânticas, agrupando as palavras com nível de significação próxima. Os procedimentos realizados seguiram os critérios de rede semântica.

Essa técnica, de forma empírica, permite acessar a estrutura cognitiva do conhecimento, apresentando informações a respeito da organização e compreensão interna dos significantes (Vera-Noriega, Pimentel, \& Batista de Albuquerque, 2005). Ela (rede semântica) sugere os seguintes procedimentos: tamanho da rede (TR), núcleo da rede (NR), peso semântico (PS) e distância semântica quantitativa (DSQ).

O TR foi obtido através da contagem das palavras evocadas pelas respondentes. Obteve-se o PS, de cada uma das palavras, somando-se as frequências pela hierarquia de importância, fornecida pelas participantes, sendo indicado pelo número 1 (um), a palavra mais próxima e multiplicada por 5 (cinco); a palavra seguinte por 2 (dois), sendo multiplicada por 4; com 3 (três) a terceira palavra; multiplicada por 3 , até ao número 5 , que é multiplicado por 1 . O NR foi obtido através das cinco palavras definidoras com peso semântico mais elevado, sendo estas as que melhor caracterizam o conceito. A DSQ foi obtida através da palavra definidora do NR; a palavra com peso semântico mais elevado foi sinalizada com valor $100 \%$, sendo as porcentagens das outras palavras obtidas com uma regra de três simples.

\section{Resultados}

A partir dos dados coletados através da TALP, foi construída a rede de significados (rede semântica) dos termos evocados através do estímulo indutor álcool, para os grupos analisados nessa pesquisa. Esses dados são apresentados a seguir.

No que se refere às universitárias que não consomem bebida etílica, o álcool foi representado, majoritariamente, como uma droga, como se verifica pelo maior peso semântico atribuído à palavra, com distância semântica de 100\%. Sendo em seguida, apontado como vício (68\%), o consumo excessivo ocasionando a dependência (60\%), 
que representa a fase da doença (20\%) na vida do usuário, estando relacionado a acidentes (17\%), uma das consequências de seu consumo.

Tabela 2

Rede semântica acerca do álcool entre universitárias que não consomem álcool

\begin{tabular}{ccc}
\hline $\begin{array}{c}\text { Núcleo da Rede } \\
\text { (NR) }\end{array}$ & $\begin{array}{c}\text { Peso Semântico } \\
\text { (PS) }\end{array}$ & $\begin{array}{c}\text { Distância Semântica } \\
\text { Quantitativa (DSQ) }\end{array}$ \\
\hline Droga & 70 & $100 \%$ \\
Vício & 48 & $68 \%$ \\
Dependência & 42 & $60 \%$ \\
Doença & 14 & $20 \%$ \\
Acidentes & 12 & $17 \%$
\end{tabular}

As participantes que consomem álcool foram submetidas ao mesmo estímulo indutor (álcool), resultando na palavra definidora diversão como a de maior peso semântico, com distância semântica de $100 \%$, seguida por comemoração (86\%) e festa (64\%). As demais informações podem ser consultadas na tabela 3.

Tabela 3

Rede semântica acerca do álcool entre universitárias que consomem álcool

\begin{tabular}{ccc}
\hline $\begin{array}{c}\text { Núcleo da Rede } \\
\text { (NR) }\end{array}$ & $\begin{array}{c}\text { Peso Semântico } \\
\text { (PS) }\end{array}$ & $\begin{array}{c}\text { Distancia Semântica } \\
\text { Quantitativa (DSQ) }\end{array}$ \\
\hline Diversão & 65 & $100 \%$ \\
Comemoração & 56 & $86 \%$ \\
Festa & 42 & $64 \%$ \\
Alegria & 16 & $24 \%$ \\
Ressaca & 13 & $20 \%$ \\
\hline
\end{tabular}

\section{Discussão}


Para discutir os resultados relatados acima, optou-se, tendo em vista tornar a leitura do texto mais fluida, apresentar esse tópico dividido em duas partes: Universitárias que não consomem álcool e Universitárias que consomem álcool. Assim, em seguida inicia-se a discussão referente ao primeiro grupo.

\section{Universitárias que não consomem álcool}

Tendo em conta a tabela 2, nota-se que essas universitárias representam o álcool enfatizando seus aspectos mais negativos, aludindo os impactos sob o indivíduo e a sociedade, evidenciados pelo elenco das palavras definidoras "doença" e "acidentes". A conceituação do álcool como uma droga, remete à ideia de que provoca modificações nas funções psíquicas, expressando a definição mais próxima que se tem do construto. Na literatura científica, o álcool é classificado como uma droga psicoativa que atua no sistema nervoso central (SNC), provocando alterações no comportamento das pessoas que o ingerem, afetando, assim, os processos de consciência, atenção, memória e orientação espacial (Formigoni, Galduróz, De Micheli, \& Carneiro, 2017). Essa ação depressora da droga, que diminui a atividade do SNC, resulta em consequências como os acidentes, definidor associado à bebida alcoólica pelas jovens.

Ao representarem o álcool como uma droga, essas estudantes enfatizam a percepção da substância como algo ruim e danoso, sendo possível inferir, a partir dessa categorização, que tal concepção atua para esse grupo como um fator de proteção, inibindo o consumo de bebidas alcoólicas.

Esta representação pode refletir as opiniões, os conceitos e a visão de mundo circundantes nos grupos religiosos, os quais estas jovens integram, uma vez que a maioria afirmou possuir religião (88\%), sendo que $50 \%$ se autodeclararam evangélicas. Os comportamentos associados a maior aderência religiosa atuam diretamente como fatores de proteção ao uso e abuso de álcool (Drabble, Trocki, \& Klinger, 2016). No entanto, algumas religiões exercem um efeito protetor maior do que 
outras. Nesse sentido, os sujeitos participantes de grupos evangélicos têm menor probabilidade de envolvimento com o consumo de álcool, uma vez que as religiões conservadoras, por meio de ensinamentos doutrinários, exercem influência direta sobre os comportamentos de seus adeptos, estabelecendo valores e normas condizentes com suas formas de perceber o mundo (Gomes, Andrade, Izbicki, Moreira-Almeida, \& Oliveira, 2013). À luz da Grande Teoria, salienta-se que as RS, que refletem o conhecimento do senso comum, são criadas e transformadas a partir de práticas e relações do cotidiano (Jodelet, 2001). Deste modo, nas representações destas estudantes a respeito do álcool como uma droga, implicam-se os aspectos religiosos, já que no espaço social em que elas estão imersas, existe uma difusão marcante dessas formas de mensagens comunicativas, ressaltando a abstinência da bebida alcoólica.

O vício aparece no campo semântico das participantes relacionado à dependência, sendo esta referenciada ao consumo excessivo de álcool, resultando no comprometimento da saúde do usuário. Relativamente aos padrões de consumo, os estudos costumam discriminar entre uso, abuso e dependência. O uso é associado ao beber de baixo risco, isto é, dentro de padrões que não comprometam à saúde, as atividades ocupacionais diárias e a segurança do indivíduo e das outras pessoas. $\mathrm{O}$ abuso, também denominado de uso nocivo, refere-se ao padrão de consumo que provoca prejuízos ao sujeito, podendo levar a dependência (Formigoni et al., 2017). A dependência é fase em que o consumo ocorre de forma contínua e periódica, sendo identificada como um estado crítico, no qual o sujeito não tem mais controle sobre o ato de ingerir bebidas alcoólicas, apresentando problemas crônicos relacionados ao consumo. Ela é classificada em dois tipos: psicológica e física. A primeira corresponde aos desconfortos psicológicos que emergem em função da abstinência do álcool, como a ansiedade, sentimento de vazio e falta de concentração, com variações interpessoais. A segunda é caracterizada pela presença de sintomas e sinais físicos 
decorrentes da abstinência do álcool no organismo, resultando em diversos sintomas orgânicos, entre eles: tremor nas mãos, náuseas, vômitos e delirium tremens (Centro Brasileiro de Informações sobre Drogas Psicotrópicas [CEBRID], 2017).

A palavra doença também foi representada pelas jovens, indicando os efeitos deletérios da droga no indivíduo. Na literatura, consoante com essa RS, o álcool aparece correlacionado a diversos problemas de saúde, tais como: doenças neuropsiquiátricas (transtornos mentais, epilepsia), doenças gastrointestinais (cirrose hepática e pancreatite), câncer (câncer de boca, laringe, esofágico, cólon, fígado, mama, etc.), doenças sexualmente transmisseveis (HIV), doenças infecciosas (tuberculose e pneumonia), entre outras (OMS, 2014).

As enfermidades associadas ao uso de álcool acabam onerando a sociedade, aumentando os custos em hospitais, gastos previdenciários, perda de produtividade e mortalidades (Bertoni \& Santos, 2017). De acordo com Leite et al. (2016), cerca de 66\% dos custos com a saúde pública estão ligados a doenças crônicas não transmissíveis, dentre elas, os problemas de adição, como o consumo de bebidas alcoólicas, são responsáveis por grande parte dos gastos do Sistema Único de Saúde (SUS), através de tratamentos e internações.

Tais evidências demonstram que, as consequências relacionadas ao consumo de álcool têm dimensões sociais amplas, transcendendo o aspecto individual. Além de representar riscos à saúde, o álcool também se mostra associado a outros fatores, como os acidentes, definidor mencionado pelas universitárias, remetente às tragédias no trânsito. Pesquisas apontam que os acidentes de trânsito, causados por consumo de álcool, constituem um grave problema de saúde pública, resultando em sequelas, gastos com internações e mortes, em especial entre a população jovem (Mello Jorge \& Adura, 2013; Araújo et al., 2015).

No Brasil, um estudo realizado pelo Ministério da Saúde (MS), em 71 hospitais públicos de 24 capitais e do Distrito Federal, apontou que, o uso de bebidas alcoólicas 
tem impacto nos atendimentos de urgência e emergência nessas instituições. Segundo a pesquisa, a cada cinco vítimas de acidentes de trânsito uma havia consumido álcool. Os dados evidenciam ainda que, do total de atendimentos por acidentes registrados, a maior proporção foi entre adolescentes e adultos jovens, sendo a faixa etária de 20 a 39 a mais acometida tanto para homens $(58,2 \%)$ quanto para mulheres $(49,3 \%)$. Entre as vítimas predominaram os condutores $(64,9 \%)$, seguidos pelos pedestres $(10,64 \%)$ e passageiros $(23,83 \%)$, sendo que $16,7 \%$ dos atendidos haviam consumido algum tipo de bebida alcoólica (Brasil, 2013).

Em outra investigação, Damacena et al. (2016) realizaram, a partir dos dados da Pesquisa Nacional de Saúde-PNS, em 2013, uma análise do consumo de álcool, relacionando-o com os acidentes de trânsito. Os pesquisadores verificaram que a proporção de pessoas que tinham se envolvido em acidentes com lesões um ano antes da PNS em 2013, foi de 3,1\% na população geral, sendo quase o dobro entre os que consumiam bebidas alcoólicas. Destes a maior parte eram do sexo masculino, com prevalência de 4,5\% na população geral e de 7,5\% entre os que ingeriam álcool. Os jovens foram os que mais se envolveram em acidentes tanto na população geral quanto entre os que consumiam álcool.

A bebida alcoólica prejudica a segurança no trânsito, afetando a percepção, a visão, os reflexos, a consciência e o comportamento das pessoas, predispondo-as à adoção de condutas de risco (Araújo et al., 2015). Além disso, o álcool também reduz a capacidade de atenção do condutor, tornando difícil manter a concentração frente aos diversos estímulos presentes no trânsito, tais como curvas, pedestres e outros veículos, aumentando, assim, os riscos de acidentes. As doses mínimas de álcool já são capazes de alterar o SNC, prejudicando a condução veicular, afetando as habilidades psicomotoras finas (como o manejo do volante para manutenção do trajeto), realizar alteração na velocidade e acionar adequadamente o freio, para manter um afastamento seguro e adequado (Mello Jorge \& Adura, 2013). 
Analisadas as representações sociais desse grupo de universitárias, em seguida discute-se a rede semântica (significados) do segundo grupo.

\section{Universitárias que consomem álcool}

A partir da tabela 3, observa-se que essas jovens representam o álcool, associando-o a significados positivos, revelando os aspectos favoráveis de seu consumo, destacado por maior proporção para os efeitos positivos (diversão, comemoração, festa e alegria) comparados aos negativos (ressaca).

O termo definidor "diversão" remete às situações de descontração, alegria, entretenimento e prazer, vinculado ao consumo de álcool. Essa RS se coaduna com que tem sido expresso em pesquisas prévias. Em um estudo realizado com universitários da área da saúde de uma Universidade Federal no Brasil, com o objetivo de identificar os fatores associados ao uso de bebidas alcoólicas, a diversão aparece como um dos motivos mais citados pelos jovens para justificar a ingestão de álcool (Baumgarten, 2010). Em outra pesquisa, cujo o intuito era investigar a relação entre lazer e álcool, 46,2 \% dos jovens relacionaram o consumo de bebidas etílicas à diversão, indicando a percepção de que o álcool é um fator necessário para se divertir (Pinto, 2013).

A relação entre álcool e diversão também emerge com destaque na pesquisa de Rosa e Nascimento (2015). O estudo foi conduzido com estudantes universitários do sexo masculino, objetivando acessar as suas representações acerca do álcool. Na referida pesquisa, a diversão aparece como um elemento periférico das representações, com alta frequência, expressando uma conotação positiva ao consumo de álcool.

A partir do exposto, percebe-se uma relação estreita entre o uso de bebidas alcoólicas e a diversão entre os jovens, trazido à tona empiricamente pela RS desse grupo de universitárias participantes desta pesquisa. A existência, manutenção e difusão desse pensamento associativo (álcool e diversão) é apontada na literatura como decorrente 
da indústria de bebidas, que massivamente investe altas cifras de capital em campanhas publicitárias. De acordo com Sousa (2017), a publicidade é uma das agências sociais que exerce maior controle na vida das pessoas, influenciando a maneira de sentir, agir e se comportar. Visando o lucro, ela atua para estimular o consumo do álcool, divulgando, de forma criativa, uma imagem favorável acerca do produto. Ao vincular cenas que relacionam o álcool às situações que expressam divertimento, as propagandas midiáticas reforçam a visão dos jovens de que não é possível se divertir sem estarem consumindo álcool, sendo, portanto, identificado como condição sine qua non para o divertimento (Pinto, 2013).

Corroborando esses argumentos, Bertolo e Romera (2011) ressaltam que os anúncios publicitários do álcool estabelecem uma aproximação entre o ato de ingerir bebidas alcoólicas e a vivência do lazer da população jovem, apresentando o álcool combinado à diversão, satisfação e prazer. Das peças publicitárias analisadas na pesquisa pelas autoras, $51,3 \%$ traziam o álcool atrelado à diversão e a seus correlatos. De acordo com Araújo et al. (2015), essa intensa propaganda estimula o consumo de álcool pelos estudantes, facilitando a utilização da substância nos momentos de socialização ou integração entre eles, dificultando a percepção da droga como um problema de saúde pública (Araújo et al., 2015).

Outra palavra mencionada pelas universitárias foi comemoração, que remete a determinadas situações festivas, nas quais o álcool aparece como um item de consumo indispensável. Ao longo do itinerário histórico, a bebida alcoólica sempre apresentou certo privilégio na sociedade, sendo um artefato utilizado nos ritos religiosos, nas comemorações e confraternizações, servindo também de laços entre as pessoas (Werner et al., 2015).

O termo definidor festas emerge no campo semântico das universitárias retratando os espaços ou locais onde ocorre o maior consumo de bebidas alcoólicas entre os jovens. Essa representação é congruente com o que foi referenciado na pesquisa de 
Pinto (2013), na qual $29,7 \%$ dos participantes indicaram as festas como os ambientes mais comuns para a ingestão de bebidas. Segundo o autor, elas constituem-se em espaços que oportunizam o lazer, a interação e socialização entre os jovens, sendo frequente a participação destes nesses eventos.

É no contexto de festas que visam integrar os jovens, onde existe grande disponibilidade de bebidas alcoólicas, ocorrendo o consumo em excesso, também chamado de binge drinking - o beber para se embriagar (Rosa \& Nascimento, 2015; Silva et al., 2015). Os jovens expostos a esses ambientes, nos quais o álcool é facilmente obtido, apresentam maior probabilidade de consumir abusivamente a substância do que aqueles que não estão expostos a esse tipo de situação (Feijão et al., 2012).

Nesse sentido, Baumgarten (2010) pontua que uma prática recorrente entre os jovens são as chamadas concentrações noturnas ou pré-night, ao qual eles se encontram em determinado local para consumir álcool, de modo que, ao se deslocarem para casas noturnas ou outras festividades, já estão sobre os efeitos da substância. Esse consumo de álcool durante as festividades pode representar uma porta de entrada para o uso de outras drogas (Silva et al., 2015).

Ao relacionarem o álcool com momentos de alegria, pode-se inferir que as estudantes fazem menção às sensações prazerosas obtidas na fase inicial do consumo da substância. Como retratam Formigoni et al. (2017), o álcool é uma droga bifásica. Assim, em um primeiro momento, atua como um estimulante (efeito primário) proporcionando ao consumidor sensações de alegria, euforia, desinibição, relaxamento, sociabilidade e prazer.

Embora essas estudantes enunciem, predominantemente, os aspectos primários do consumo de álcool, indicando uma valorização da bebida como um produto indispensável em contextos de festas, comemoração e diversão, elas também esboçam entendimento de efeitos negativos do uso excessivo de álcool, como 
evidenciado pela palavra "ressaca". Todavia, esta surge na rede, distante das demais palavras enunciadas, podendo-se cogitar que, para este grupo, as consequências negativas ocasionadas pelo uso de álcool, aparecem de forma secundária. O termo ressaca é usado para expressar os desconfortos vivenciados após períodos de intenso consumo de bebidas alcoólicas em festas e outros eventos, sendo caracterizada por sintomas que surgem algumas horas após a ingestão de uma quantidade elevada de álcool, como dor de cabeça, náusea, fadiga muscular, vômitos, entre outros (Formigoni et al., 2017).

Pelos dados apresentados, verifica-se que o álcool aparece atrelado a duas facetas ensejadas por posturas que, de um lado, ressalta a abstinência total da bebida alcoólica e, do outro, à defesa em relação ao uso da substância marcada por simbolismos que culturalmente favorecem a sua ingestão, especialmente entre a população jovem.

\section{Considerações Finais}

Este estudo abordou as representações sociais das universitárias brasileiras a respeito do álcool, substância psicoativa amplamente consumida na atualidade. A partir dos dados obtidos, foi possível observar RS consensuais e particulares, de acordo com cada um dos grupos. As universitárias que afirmaram não consumir álcool enfatizaram os problemas psicossociais decorrentes do uso da bebida alcoólica, associando-a a droga, o vício, a dependência, a doença e os acidentes. Deste modo, verifica-se que elas ancoram suas representações retomando a seriedade da questão do uso do álcool, identificado como uma aporia social. Por outro lado, as estudantes que utilizam álcool resgatam os momentos prazerosos proporcionados pelo uso da bebida, revelando representações predominantemente positivas sobre o álcool (diversão, comemoração, festa, alegria), embora seja evidenciado efeitos indesejados, a ressaca. 
As RS se constituem em um saber prático que orienta as ações e condutas das pessoas. Desta maneira, o acesso às crenças compartilhadas por essas universitárias brasileiras sobre o álcool, possibilitou o entendimento que as mesmas possuem acerca da substância, obtendo-se acesso aos motivos que as levam a consumir ou não bebidas alcoólicas. Esses dados são de grande valia, uma vez que permitem subsidiar ações preventivas direcionadas a esse público, condizentes com suas características e necessidades, contribuindo, assim, para melhores cuidado em saúde no espaço universitário.

Além disso, cabe salientar que as mulheres são mais sensíveis aos efeitos do álcool, alcançando níveis mais altos de concentração no sangue com quantidades menores da substância, chegando com mais rapidez ao estado de embriagues. Ademais, o uso de bebida etílica também figura como uma porta de entrada para a experimentação de outras drogas. Assim, parece plausível a realização de investigações voltadas para o estudo do uso de bebidas alcoólicas por estudantes universitárias, que contribuam para minimizar o risco e potencializar os fatores de proteção, tendo em vista que estas integram um ambiente onde esse consumo é potencializado. Apesar deste estudo possibilitar a compreensão das RS do álcool entre estudantes universitárias, reconhece-se que o mesmo apresenta limitações em relação às participantes, uma vez que foi considerado apenas universitárias de uma única IES pública, não havendo a investigação com estudantes de outras IES, como as privadas. Ressalta-se ainda se trata de um estudo pontual, não tendo como pretensão esgotar a discussão da temática. Desta forma, sugere-se a realização de outras pesquisas que ampliem o número de partícipes, contemplando universitárias de IES púbicas e privadas em diferentes regiões do país. 


\section{Referências}

Araújo, T. A., Oliveira, A. D. S., Souza, I. B. J, Silva, F. J. G., Jr., Nery, I. S., \& Monteiro, C. F. S. (2015). Traffic accidents and their relationship with alcohol use: integrative review. Journal of Nursing UFPE On Line, 9(Supl. 5), 84378443. doi: 10.5205/reuol.6466-55061-3-SM.0905supl201513

Barros, C. V. L., Barros, D. A. C., Bernardes, M. J. C., Lima, W. V., \& Silva, L. C. S. (2012). A influência do convívio universitário na adesão ao alcoolismo. Itinerarius Reflectionis, 2(13), 1-12. Recuperado de https://www.revistas.ufg.br/rir/article/view/ 22312/19235

Baumgarten, L. Z. (2010). Padrão de consumo de bebidas alcoólicas entre acadêmicos (as) dos cursos da área da saúde (Dissertação de mestrado). Escola de Enfermagem do PPGE, Universidade Federal do Rio Grande, Rio Grande, RS, Brasil.

Bertolo, M. A., \& Romera, L. A. (2011). Cerveja e publicidade: uma estreita relação entre lazer e consumo. Licere, 14(2), 1-27. Recuperado de https://seer.ufmg.br/index.php/licere/article/view/500/392

Bertoni, L. M., \& Santos, R. V. R. (2017). Alcoolismo e meio rural. Revista GeoNordeste, $\quad 1, \quad 98-113 . \quad$ Recuperado de https://seer.ufs.br/index.php/geonordeste/article/view/6122/pdf

Brasil, Ministério da Saúde (2013). Sistema de Vigilância de violências e acidentes (VIVA):2009, 2010, 2011. Brasília: Editora MS.

Centro Brasileiro de Informações sobre Drogas Psicotrópicas (2017). Dependência. São Paulo: UNIFESP. Recuperado de http://www2.unifesp.br/dpsicobio/cebrid/quest_drogas/dependencia.htm

Coutinho, M. P. L., \& Do Bú, E. (2017). A técnica de associação livre de palavras sobre o prisma do software tri-deux-mots (version 5.2). Revista Campo do Saber, 
$3(1)$,

219-243.

Recuperado

de

http://periodicos.iesp.edu.br/index.php/campodosaber/article/view/72

Damacena, G. N., Malta, D. C., Boccolini, C. S., Souza, P. R. B., Jr., Almeida, W. D.,

Ribeiro, L. S., \& Szwarcwald, C. L. (2016). Alcohol abuse and involvement in traffic accidents in the Brazilian population, 2013. Ciência \& Saúde Coletiva, 21(12), 3777-3786. doi: 10.1590/1413-812320152112.25692015

Drabble, L., Trocki, K. F., \& Klinger, J. L. (2016). Religiosity as a protective factor for hazardous drinking and drug use among sexual minority and heterosexual women: Findings from the National Alcohol Survey. Drug and Alcohol Dependence, 161, 127-134. doi: 10.1016/j.drugalcdep.2016.01.022

Feijão, I. E. P., Sampaio, H. A. C., Sabry, M. O. D., Carioca, A. A. F., Yum, M. E. M., \& Lima, J. W. O. (2012). Prática de binge alcoólico entre estudantes universitários. Revista Brasileira em Promoção da Saúde, 25(4), 462-468. Recuperado de http://www.redalyc.org/pdf/408/40824829010.pdf

Formigoni, M. L. O. S., Galduróz, J. C. F., De Micheli, D., \& Carneiro, A. P. L. (2017). Álcool: efeitos agudos e crônicos. In P. C. A. V. Duarte, \& M. L. O. S. Formigoni (Orgs), Efeitos das substâncias psicoativas (pp. 45-70). Brasília: SENAD

Gomes, F. C., Andrade, A. G., Izbicki, R., Moreira-Almeida, A., \& Oliveira, L. G. (2013). Religion as a protective factor against drug use among Brazilian university students: a national survey. Revista Brasileira de Psiquiatria, 35(1), 29-37. doi: 10.1016/j.rbp.2012.05.010

Jodelet, D. (2001). Representações Sociais. Rio de Janeiro, RJ: UERJ.

Leite, J. C. A., Leite, N. G. D., Soares, W. D., \& Finelli, L. A. C. (2016). Consumo de álcool entre os acadêmicos de enfermagem. Revista Bionorte, 5(1), 50-58. Recuperado de http://www.revistabionorte.com.br/arquivos_up/artigos/a36.pdf

II LENAD (2012). II Levantamento Nacional de Álcool e Drogas. São Paulo: Instituto Nacional de Ciência e Tecnologia para Políticas Públicas de Álcool e Outras 
Drogas. Recuperado de http://inpad.org.br/wp-content/uploads/2014/03/LenadII-Relat\%C3\%B3rio.pdf

Mello Jorge, M. H. P., \& Adura, F. E. (2013). Álcool e direção veicular. Revista USP, 96, 23-36. doi: 10.11606/issn.2316-9036.v0i96p23-36

Moscovici, S. (2015). Representações sociais: investigações em psicologia social. Petrópolis, RJ: Vozes.

Pinto, V., Jr. (2013). Lazer e álcool: o perfil dos estudantes de estudantes de educação física da universidade federal do espírito (Trabalho de conclusão de curso). Universidade Federal do Espírito Santo, Vitória, ES, Brasil.

Rosa, L. F. A., \& Nascimento, A. R. A. (2015). Representações sociais de bebida alcoólica para homens universitários. Arquivos Brasileiros de Psicologia, 67(1), 3-19. Recuperado de http://pepsic.bvsalud.org/pdf/arbp/v67n1/02.pdf

Silva, J. N., Rodrigues, M. G., Jones, K. M., Finelli, L. A. C., \& Soares, W. D. (2015). Consumo álcool entre universitários. Revista. Brasileira de Pesquisa em Ciências da Saúde. 2(2), 35-40. Recuperado de http://revistas.icesp.br/index.php/RBPeCS/article/view/45/44

Sousa, K. P. A. (2017). Alguns fatores que influenciam o consumo precoce de álcool. Revista Espaço Acadêmico, 193, 92-101. Recuperado de http://www.periodicos.uem.br/ojs/index.php/EspacoAcademico/article/view/3344 $7 / 19461$

Vera-Noriega, J., Pimentel, C., \& Batista de Albuquerque, F. (2005). Redes semânticas: aspectos teóricos, técnicos, metodológicos y analíticos. Ra Ximhai, 1(3), 439-451. Recuperado de http://www.redalyc.org/articulo.oa?id=46110301

Werner, M. E. C., Siqueira, M. F. C., \& Lemes, A. G. (2015). Consumo alcoólico entre universitários: vamos discutir essa ideia? Revista Eletrônica Interdisciplinar, 13(1), 42-48. $\quad$ Recuperado de 
https://www.researchgate.net/publication/322527332_Consumo_alcoolico_entr e_universitarios_Vamos_discutir_essa_ideia

World Health Organization [Organização Mundial da Saúde, OMS] (2014). Global status report on alcohol and health. Geneva: World Health Organization.

Formato de citación

Pereira, K., De Medeiros, E., Fernandes de Araujo, L., Pereira, R. (2018). Representações sociais do álcool entre estudantes universitárias brasileiras. $\begin{array}{llll}\text { Psicología, Conocimiento } \quad y \quad \text { Sociedad, } & \text { PREPRINT, }\end{array}$ doi: http://dx.doi.org/10.26864/PCS.v9.n1.2 